\title{
Association between amygdala neurokinin- 1 receptor availability and anxiety-related personality traits
}

Johanna M. Hoppe ${ }^{1}$, Andreas Frick $\mathbb{B D}^{1,2}$, Fredrik Åhs ${ }^{1,3}$, Clas Linnman ${ }^{4}$, Lieuwe Appel ${ }^{5}$, My Jonasson 5,6, Mark Lubberink ${ }^{5,6}$, Bengt Långström ${ }^{7}$, Örjan Frans ${ }^{1}$, Lars von Knorring $\mathbb{1}^{8}$, Mats Fredrikson ${ }^{1,3}$ and Tomas Furmark ${ }^{1}$

\begin{abstract}
Animal studies indicate that substance P (SP) and its preferred neurokinin-1 (NK1) receptor modulate stress and anxiety-related behavior. Alterations in the SP-NK1 system have also been observed in human anxiety disorders, yet little is known about the relation between this system and individual differences in personality traits associated with anxiety propensity and approach-avoidance behavior, including trait anxiety, neuroticism, and extraversion. Exploring this relation could provide important insights into the neurobiological underpinnings of human anxiety and the etiology of anxiety disorders, as anxious traits are associated with increased susceptibility to develop psychopathological conditions. Here we examined the relationship between central NK1 receptor availability and selfrated measures of trait anxiety, neuroticism, and extraversion. The amygdala was chosen as the primary region of interest since this structure has been suggested to mediate the effect of the SP-NK1 system on anxiety. Anxious traits and NK1 receptor availability, determined with positron emission tomography and the radiotracer $\left[{ }^{11} \mathrm{C}\right] \mathrm{GR} 205171$, were measured in 17 healthy individuals. Voxel-wise analyses showed a significant positive correlation between bilateral amygdala NK1 receptor availability and trait anxiety, and a trend in similar direction was observed for neuroticism. Conversely, extraversion was found to be negatively associated with amygdala NK1 receptor availability. Extraversion also correlated negatively with the NK1 measure in the cuneus/precuneus and fusiform gyrus according to exploratory whole-brain analyses. In conclusion, our findings indicate that amygdala NK1 receptor availability is associated with anxiety-related personality traits in healthy subjects, consistent with a modulatory role for the SP-NK1 system in human anxiety.
\end{abstract}

\section{Introduction}

The neuropeptide substance $\mathrm{P}(\mathrm{SP})^{1}$ and its preferred neurokinin-1 receptor $(\mathrm{NK} 1)^{2}$ are abundantly distributed in the mammalian nervous system, including structures in the brain's fear network such as the amygdala ${ }^{3,4}$. Animal studies provide evidence that the SP-NK1 system modulates stress and anxiety-related behavior ${ }^{3,5}$ and alterations in this system have also been suggested to be

\footnotetext{
Correspondence: Johanna M. Hoppe (johanna.motilla_hoppe@psyk.uu.se) 'Department of Psychology, Uppsala University, Uppsala, Sweden ${ }^{2}$ Department of Psychology, Stockholm University, Stockholm, Sweden Full list of author information is available at the end of the article. These authors contributed equally: Mats Fredrikson, Tomas Furmark
}

involved in human anxiety disorders ${ }^{6-8}$. For instance, patients with social anxiety disorder (SAD), as compared to healthy subjects, have increased NK1 receptor availability in the right amygdala ${ }^{9}$ and treatment with the NK1 receptor antagonist GR205171 has been shown to alleviate social anxiety in parallel with decreased regional cerebral blood flow in the amygdala during public speaking ${ }^{10}$. Also, in a positron emission tomography (PET) study of patients with specific phobia, exposure to phobic, as compared to non-phobic, stimuli was associated with a reduced uptake of the radiotracer $\left[{ }^{11} \mathrm{C}\right]$ GR205171 in the amygdala, putatively reflecting increased release of endogenous $\mathrm{SP}^{11}$. Moreover, elevated 
cerebrospinal fluid SP concentration and increased amygdala NK1 receptor availability have been observed in patients with posttraumatic stress disorder, compared with healthy subjects ${ }^{12,13}$. Notably, whereas beneficial effects of NK1 receptor antagonists were observed initially in experimental and clinical studies, these effects could not be confirmed in phase III clinical trials ${ }^{10,14-16}$. However, despite these mixed results, converging findings from several studies indicate that the SP-NK1 system is part of the neural underpinnings of anxiety disorders ${ }^{9-13}$. Furthermore, it has been argued that the negative results from phase III trials could be influenced by several factors, such as use of inadequate drug dose range, use of NK1 receptor antagonist drugs with insufficient pharmacokinetic and pharmacodynamic properties, as well as heterogeneous patient selection ${ }^{8,17}$. In sum, as the role of the SP-NK1 system in human anxiety is still not fully understood, further knowledge of this system is important to understand the neurobiological basis of psychopathological conditions.

Only a few studies have explored the role of the SP-NK1 system in anxiety in healthy subjects ${ }^{18-21}$. Thus, it is not known if alterations in the SP-NK1 system occur primarily in psychiatric disorders, or if they extend also to personality traits associated with anxiety propensity and approach-avoidance behavior, such as trait anxiety ${ }^{22}$, neuroticism and the extraversion-introversion dimen$\operatorname{sion}^{23}$. Even though there are studies demonstrating that administration of NK1 receptor antagonists affects some aspects of anxiety-related emotional processes in healthy subjects ${ }^{18-20}$, the relation between individual differences in anxious personality traits and the neurochemical properties of the SP-NK1 system is incompletely understood.

Anxiety-related personality traits are associated with poorer quality of life, increased susceptibility to develop psychopathological states ${ }^{24-26}$ and they impose high societal $\operatorname{cost}^{27}$. Further knowledge of their etiology is therefore essential. A biological basis for personality traits has been suggested ${ }^{28}$, and individual differences in trait anxiety, neuroticism and extraversion have been related to alterations in brain function, including altered amygdala reactivity and connectivity ${ }^{29-31}$. Animal models of anxiety $^{32,33}$ indicate that the SP-NK1 system may be involved in the neural underpinnings of anxiety-related traits. For example, rats bred to exhibit highly anxious behavior, show increased stress-induced release of SP in the medial amygdala in comparison to their low anxiety counterpart $^{34}$. Also, the response to NK1 receptor antagonists is modulated by differences in affective temperament, altering anxious behavior only in rats with high trait anxiety $^{35}$. Furthermore, pointing towards a relation between the SP-NK1 system and extraverted behavior, acute administration of NK1 receptor antagonists has been observed to increase the duration of social contact in gerbils $^{36,37}$. Collectively, these results suggest that the SPNK1 system is involved in the propensity for anxiety and approach-avoidance behavior. Individual differences in the SP-NK1 system could therefore play a role not only in psychiatric disorders, but also more generally in anxietyrelated personality traits.

The aim of the present study was to evaluate the association between the SP-NK1 system and anxious traits in healthy volunteers. We used PET and the highly selective NK1 receptor antagonist GR205171 ${ }^{38}$ labeled with $\left[{ }^{11} \mathrm{C}\right]$ as a radioligand ${ }^{39,40}$ to examine the relationship between NK1 receptor availability in the amygdala and self-report measures of trait anxiety, neuroticism, and extraversion ${ }^{23}$. The amygdala was selected as the primary region of interest since previous studies suggest that this structure modulates the effect of the SP-NK1 system on anxiety both in animals and in humans ${ }^{9-11,20,41-43}$ and because amygdala reactivity and connectivity are related to anxious traits ${ }^{30,31,44-46}$. Exploratory whole-brain analyses were, however, also performed. We hypothesized that trait anxiety and neuroticism would be positively associated with NK1 receptor availability in the amygdala, reflecting a presumed anxiogenic effect of the SP-NK1 system. Conversely, we predicted a negative association between amygdala NK1 receptor availability and the degree of extraversion, i.e., higher availability in less extraverted individuals.

\section{Materials and methods Participants}

In total 18 healthy subjects were recruited through advertising. Participants underwent a medical examination, and the Mini International Neuropsychiatric Interview ${ }^{47}$ was performed by a psychiatrist to exclude current or previous history of psychiatric disorder according to DSM-IV. Exclusion criteria were alcohol/drug abuse, neurological disorder, somatic disease, chronic use of prescription medication, left handedness, previous PET examination, family history of cancer, pregnancy and menopause. Due to technical problems, PET data from one participant could not be analyzed, leaving a sample of 17 participants ( $\mathrm{M} \pm \mathrm{SD}$ age: $34.7 \pm 9.8$ years; 9 women). There were no significant differences in age between men and women $(t(15)=0.59, P=0.56)$. The current sample has been described previously, e.g., in comparison to patients with social anxiety disorder"

The study was approved by the Uppsala University Medical Faculty Ethical Review Board and the Radiation Ethics Committee at Uppsala University Hospital. Written informed consent was obtained from all participants before the study start. 


\section{Assessment of anxiety-related traits}

Trait anxiety was assessed with the Spielberger StateTrait Anxiety Inventory (STAI-T) ${ }^{22}$ and the personality traits neuroticism and extraversion, were measured using the self-rated version of the Revised NEO Personality Inventory (NEO PI-R) ${ }^{23}$.

\section{Radioligand}

$\left[{ }^{11}\right.$ C]GR205171 is a highly selective NK1 receptor antagonist radiotracer with high affinity and good bloodbrain barrier penetration ${ }^{38-40}$. This radiotracer shows slow dissociation from the NK1 receptor and has therefore been suggested to be suitable for assessments of NK1 receptor density ${ }^{39}$.

\section{PET image acquisition and preprocessing}

Image acquisition was performed using an ECAT Exact HR + PET scanner (Siemens/CTI, Knoxville, TN, USA) with an axial field of view of $155 \mathrm{~mm}$. Subjects were instructed to fast for $3 \mathrm{~h}$ and refrain from alcohol, caffeine, and tobacco $12 \mathrm{~h}$ before the PET-investigation. Subjects were positioned supine in the PET scanner with their heads gently fixated and a venous catheter was inserted. Each PET-investigation commenced with a 10-min transmission scan using 3 retractable germanium $\left({ }^{68} \mathrm{Ge}\right)$ rotating line sources.

The radiotracer $\left[{ }^{11} \mathrm{C}\right]$ GR205171 was injected intravenously as a fast bolus simultaneously with the start of the emission scan. Data were acquired in three-dimensional (3D) mode and consisted of 17 frames $(4 \times 60 \mathrm{~s}, 3 \times 120 \mathrm{~s}$, $10 \times 300 \mathrm{~s}$ ) with a total duration of $60 \mathrm{~min}$. Participants were scanned in the resting state and received on average 398 (SD: 11) $\mathrm{MBq}$, equal to 6 (SD: 1) $\mathrm{MBq} / \mathrm{kg}$ body weight. To facilitate spatial normalization, a $\left[{ }^{15} \mathrm{O}\right]$ water PET scan was acquired ( 3 frames $\times 30 \mathrm{~s}$ ) with administration of $\sim 10 \mathrm{MBq} / \mathrm{kg}$ body weight during the resting state. Dynamic images were reconstructed using ordered subset expectation maximization with six iterations and eight subsets and a $4 \mathrm{~mm}$ Hanning post-filter ${ }^{9}$.

Parametric $\left[{ }^{11} \mathrm{C}\right]$ GR205171 images showing influx rate $\mathrm{K}_{\mathrm{i}}\left(\mathrm{ml} \mathrm{cm}^{-3} \mathrm{~min}^{-1}\right)$ for each voxel, indexing NK1 receptor availability, were generated applying reference Patlak graphical analysis ${ }^{48,49}$ using a time interval of 30-60 min depicting irreversible tracer binding. The cerebellum was chosen as the reference region as it displays a paucity of NK1 receptors ${ }^{39,50,51}$. Cerebellum was defined using the co-registered $\left[{ }^{15} \mathrm{O}\right]$ water PET scan of each participant and the PVElab software ${ }^{52}$, an observer-independent probabilistic approach for automatic generation of volumes of interest, and transferred to the dynamic $\left[{ }^{11} \mathrm{C}\right]$ GR205171 image to obtain a cerebellum time-activity curve.

Each individual's $\left[{ }^{11} \mathrm{C}\right] \mathrm{GR} 205171 \mathrm{~K}_{\mathrm{i}}$ image was coregistered to their $\left[{ }^{15} \mathrm{O}\right]$ water summation image using affine transformation. The $\left[{ }^{15} \mathrm{O}\right]$ water summation image was then normalized to the PET template from Statistical Parametric Mapping 8 (SPM8; Wellcome Department of Cognitive Neurology, University College London, www.fil. ion.ucl.ac.uk), and the calculated transformation parameters were applied to the $\left[{ }^{11} \mathrm{C}\right] \mathrm{GR} 205171 \mathrm{~K}_{\mathrm{i}}$ image, resulting in $\left[{ }^{11} \mathrm{C}\right] \mathrm{GR} 205171 \mathrm{~K}_{\mathrm{i}}$ images normalized to the Montreal Neurological Institute (MNI) standard space with isotropic $2 \times 2 \times 2 \mathrm{~mm}^{3}$ voxels. The MNI normalized images were subsequently smoothed with a $12 \mathrm{~mm}$ isotropic Gaussian kernel to enhance the signal to noise ratio.

\section{Statistical analysis}

Participant characteristics and behavioral data were analyzed using IBM SPSS Statistics for Windows, version 22 (IBM Corp., Armonk, NY), whereas statistical analyses of PET data were conducted using SPM8 (Welcome Department of Cognitive Neurology, University College London, www.fil.ion.ucl.ac.uk). The amygdala was chosen as the primary region of interest (ROI) based on previous findings suggesting that this structure mediates the effect of the SP-NK1 system on anxiety ${ }^{9-11,20,41-43}$. The Automated Anatomical Labeling library from the Wake Forest University Pickatlas ${ }^{53}$ was used to define the amygdala, i.e., the right and left amygdala ROIs were included jointly in all analyses. Exploratory whole-brain analyses were performed in addition to ROI analyses. Age and sex were entered as covariates in all analyses since NK1 receptor availability has been suggested to be moderated by these variables $^{54,55}$. For ROI analyses, the statistical threshold for significance was set at $P<0.05$ family wise error (FWE) corrected for multiple comparisons, and exploratory whole-brain analyses were additionally performed using a combined criterion with the uncorrected statistical threshold set at $P<0.001$ at the voxel level and $P<$ 0.05 for cluster extent.

To explore the relationship between trait anxiety, neuroticism, extraversion, and NK1 receptor availability within the amygdala, parametric $\left[{ }^{11} \mathrm{C}\right] \mathrm{GR} 205171 \mathrm{~K}_{\mathrm{i}}$ images were entered into three separate regression models using the total scores for STAI-T and NEO PI-R subscales for neuroticism and extraversion as predictors. The same analyses were also performed using the extracted mean $\left[{ }^{11} \mathrm{C}\right]$ GR205171 $\mathrm{K}_{\mathrm{i}}$ value within the bilateral amygdala, i.e., the same ROI used in previous analyses. Additionally, in order to assess the specific associations between NK1 receptor availability and each of the studied anxietyrelated traits, parametric $\left[{ }^{11} \mathrm{C}\right] \mathrm{GR} 205171 \mathrm{~K}_{\mathrm{i}}$ images were entered into a multiple regression with the total scores for all traits, i.e., STAI-T, neuroticism and extraversion, as predictors. Moreover, to further evaluate the association between amygdala NK1 receptor availability and anxious traits, the total scores for each trait were also entered into a principal component analysis (PCA), extracting scores 
Table 1 Descriptive statistics and correlations of selfreport data for trait anxiety (STAI-T), neuroticism and extraversion as measured with NEO-PI-R

\begin{tabular}{llll}
\hline & Trait anxiety & Neuroticism & Extraversion \\
\hline Descriptive statistics & & & \\
Mean & 29.1 & 62.8 & 126.5 \\
SD & 7.0 & 23.9 & 13.4 \\
Range & $20-45$ & $36-122$ & $101-154$ \\
Correlations $^{\mathrm{a}}$ & & & \\
Trait anxiety & 1 & 0.72 & -0.06 \\
& & $P=0.001$ & $P=0.82$ \\
Neuroticism & - & 1 & -0.15 \\
& - & - & $P=0.57$ \\
Extraversion & - & & 1 \\
\hline
\end{tabular}

${ }^{\mathrm{a} P e a r s o n}$ correlation coefficient

for each participant on two principal components, and subsequently assessing their correlation with mean amygdala NK1 receptor availability. Furthermore, regression models with the remaining NEO PI-R factors, i.e., openness, agreeableness and conscientiousness, were conducted to control for associations between NK1 availability and non-anxious personality traits. Finally, ratings of state anxiety experienced during the PET scan, as measured with STAI- $\mathrm{S}^{22}$, were entered as a covariate of no interest in the STAI-T regression model to control for the influence of state anxiety on the association between NK1 receptor availability and trait anxiety.

\section{Results}

Descriptive statistics and correlations for personality traits are listed in Table 1 . Whereas trait anxiety and neuroticism were positively correlated, extraversion was not significantly associated with any of the other studied traits. The present sample had mean scores that were numerically somewhat lower for neuroticism and higher for extraversion, as well as showed lower variance in extraversion scores, in comparison to the Swedish normative group for NEO PI-R (neuroticism: $\mathrm{M}=78.0, \mathrm{SD}=$ 22.5; extraversion: $\mathrm{M}=107.6, \mathrm{SD}=20.7)^{56,57}$.

Age and sex corrected statistical parametric mapping revealed a positive association between NK1 receptor availability in the bilateral amygdala and trait anxiety as measured with STAI-T (Table 2, Fig. 1). We also found a trend towards a positive association between neuroticism and NK1 receptor availability bilaterally in the amygdala (right: MNI $x, y, z: 30,4,-28 ; Z=2.34, P_{\text {uncorr }}=0.010$, $152 \mathrm{~mm}^{3}$; left: MNI $x, y, z:-18,-2,-22 ; Z=2.25, P_{\text {uncorr }}$ $=0.012,208 \mathrm{~mm}^{3}$ ). Extraversion was negatively associated with NK1 receptor availability in the right amygdala
Table 2 Statistical parametric mapping of significant associations between amygdala NK1 receptor availability, trait anxiety, and extraversion in healthy subjects

\begin{tabular}{lllllll}
\hline NK1 receptor availability & $\boldsymbol{Z}$ & $\boldsymbol{P}_{\boldsymbol{F W E}}$ & Volume $^{\mathbf{a}}$ & $\boldsymbol{x}$ & $\boldsymbol{y}$ & $\boldsymbol{z}^{\mathbf{b}}$ \\
\hline Positive association & & & & & & \\
Trait anxiety & & & & & & \\
Right amygdala & 4.10 & 0.002 & 112 & 30 & 4 & -28 \\
Left amygdala & 3.56 & 0.010 & 176 & -18 & -2 & -22 \\
Negative association & & & & & & \\
Extraversion & & & & & & \\
Right amygdala & 3.25 & 0.026 & 64 & 34 & -2 & -22 \\
\hline
\end{tabular}

a Volume in $\mathrm{mm}^{3}$, voxel size: $8 \mathrm{~mm}^{3}$

${ }^{\mathrm{b}}$ Peak voxel coordinates in MNI (Montreal Neurological Institute) space

(Table 2, Fig. 1), and at an uncorrected p-level in the left amygdala (MNI $x, y, z:-28,-8,-12 ; Z=2.48, P_{\text {uncorr }}=$ $\left.0.007,240 \mathrm{~mm}^{3}\right)$. Mean NK1 receptor availability $\left(\left[{ }^{11} \mathrm{C}\right]\right.$ GR205171 $\mathrm{K}_{\mathrm{i}}$ ) within the bilateral amygdala was also positively associated with STAI-T $(r=0.59, P=0.010)$ and negatively with extraversion $(r=-0.44, P=0.049)$.

The associations between NK1 receptor availability, trait anxiety (right: MNI $x, y, z: 32,4,-26 ; Z=3.64, P_{F W E}$ $=0.010,144 \mathrm{~mm} ;{ }^{3}$ left: MNI $x, y, z:-26,0,-28 ; Z=3.39$, $P_{F W E}=0.021,72 \mathrm{~mm}^{3}$ ) and extraversion (right: MNI $x, y$, $z: 32,-2,-22 ; \quad Z=3.67, \quad P_{F W E}=0.009,288 \mathrm{~mm}^{3}$ ), remained significant also when including all traits as predictors in a single multiple regression analysis. No significant association was observed between NK1 receptor availability and neuroticism in the multiple regression. However, when removing STAI-T scores from the model, controlling only for extraversion, a trend towards a positive association between neuroticism and NK1 receptor availability was observed bilaterally in the amygdala (right: MNI $x, y, z: 30,4,-28 ; Z=2.19, P_{\text {uncorr }}$ $=0.014,96 \mathrm{~mm}{ }^{3}$ left: MNI $x, y, z:-18,0,-22 ; Z=2.09$, $P_{\text {uncorr }}=0.018,120 \mathrm{~mm}^{3}$ ). The association between amygdala NK1 receptor availability and trait anxiety remained significant also when controlling for rating of state anxiety during the PET scan (STAI-S: $\mathrm{M}=25.6$, SD $=5.2$; right: MNI $x, y, z: 30,4,-28 ; Z=3.77, P_{F W E}=$ $0.006,88 \mathrm{~mm} ;{ }^{3}$ left: MNI $x, y, z:-18,-2,-22 ; \mathrm{Z}=3.83$, $\left.P_{F W E}=0.046,8 \mathrm{~mm}^{3}\right)$. No association was found between state anxiety (STAI-S) scores and NK1 receptor availability.

Results from the PCA performed on the total scores from the anxious traits revealed one principal component (PC1) comprising trait anxiety and neuroticism with loadings of 0.91 and 0.92 respectively, whereas extraversion loaded strongly (0.97) on a second component (PC2). PC1 and PC2 explained 58\% and 33\% respectively of the variance in anxiety-related traits. Subsequent bivariate 


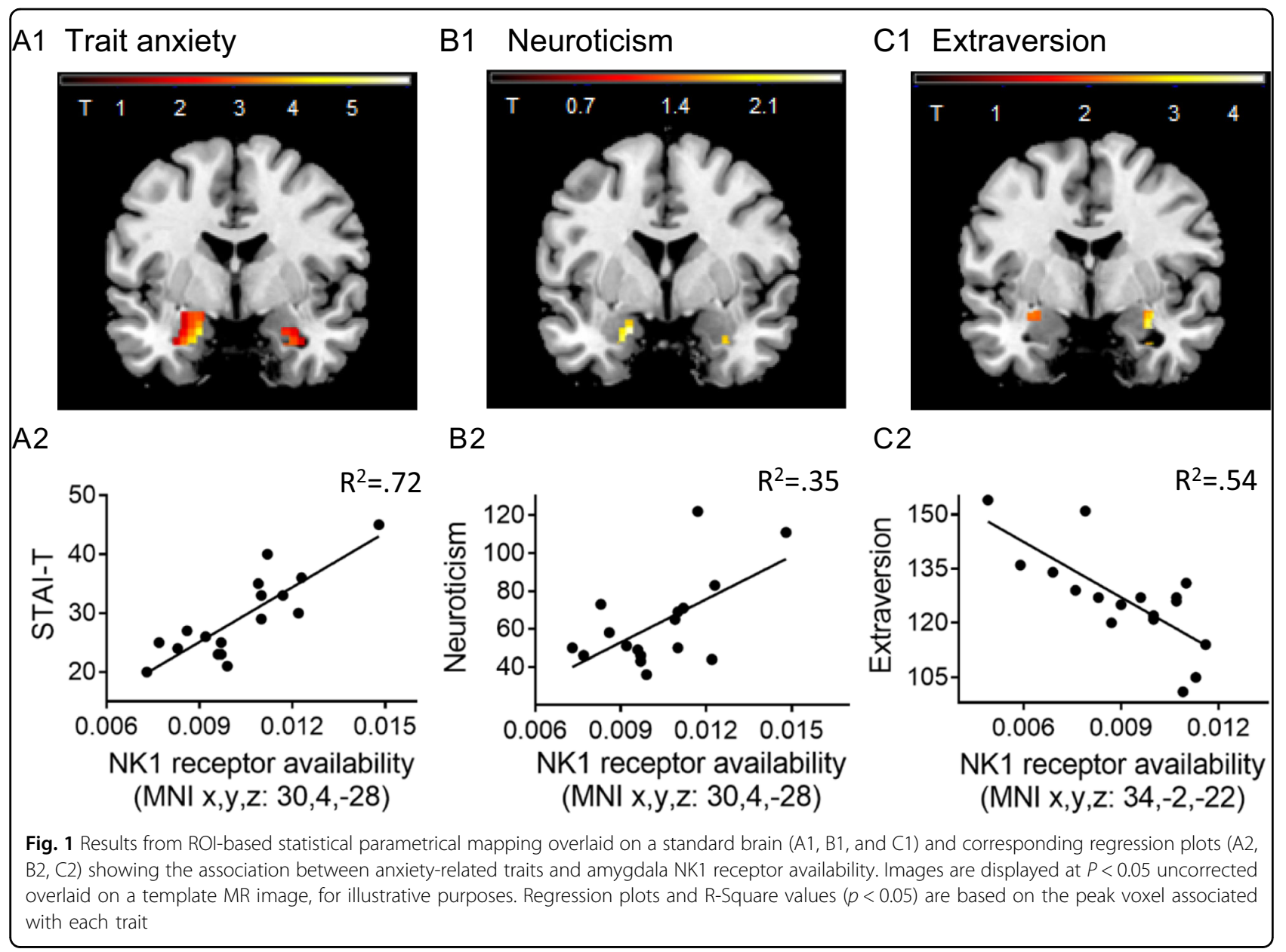

correlation analyses showed a positive association between mean amygdala NK1 receptor availability and scores on PC1, i.e., trait anxiety and neuroticism $(r=0.49$, $p=0.048)$, but no significant association was observed with scores on $\mathrm{PC} 2$, i.e., extraversion $(r=-0.30, p=$ 0.25).

Exploratory whole-brain analysis showed no significant associations, within any brain region, between NK1 receptor availability and trait anxiety or neuroticism, respectively. However, a negative association was found between extraversion and NK1 receptor availability within the right precuneus/cuneus (MNI $x, y, z: 10,-84,38 ; Z=$ 4.68, $P_{\text {uncorr }}<0.001,2240 \mathrm{~mm}^{3}$, Brodmann area 19 and MNI $x, y, z: 10,-72,20 ; Z=3.93, \quad P_{\text {uncorr }}<0.001$, $3600 \mathrm{~mm}^{3}$, Brodmann area 31) and left fusiform gyrus (MNI $x, y, z:-28,-68,-10 ; Z=4.30, P_{\text {uncorr }}<0.001$, $1856 \mathrm{~mm}^{3}$, Brodmann area 19$)$.

NK1 receptor availability was not significantly associated with any of the remaining NEO PI-R scales, i.e., openness, agreeableness, or conscientiousness, in the amygdala or any other brain region.

\section{Discussion}

Our aim was to evaluate the association between NK1 receptors and anxiety-related traits in healthy subjects. The results were in line with our hypotheses, showing a positive association between amygdala NK1 receptor availability and trait anxiety as well as a negative association between the amygdala NK1 measure and extraversion. NK1 receptor availability and neuroticism were also positively correlated, but only at statistical trend level. In addition, our results suggest that NK1 receptor availability may be specific to anxiety-related traits, since no association was observed with either of the remaining non-anxious NEO PI-R personality traits. Thus, we demonstrate that various anxiety-related traits are linked to amygdala NK1 receptor availability in a non-psychiatric population, consistent with previous findings indicating a role for the SP-NK1 system in human anxiety ${ }^{9-13,18-20}$.

The positive association between trait anxiety and amygdala NK1 receptor availability supports previous observations of an anxiogenic role of the SP-NK1 system $^{9-13}$, and it is in good agreement with studies showing 
that the effect of the SP-NK1 system on anxiety is mediated by the amygdala ${ }^{41-43}$. Even though the relation between amygdala NK1 availability and neuroticism only emerged at a statistical trend level, the association was in the hypothesized direction, i.e., same as for trait anxiety (see Fig. 1). Furthermore, our findings are consistent with imaging studies showing that trait anxiety and neuroticism are associated with altered amygdala func$\operatorname{tion}^{31,44,45,58}$. Thus, it could be speculated that the relation between these traits and amygdala function involves the SP-NK1 system.

Extraversion is associated with the propensity for approach behavior and experiencing positive affect ${ }^{23,59}$. As predicted, we noted a negative correlation between this personality trait and amygdala NK1 receptor availability, i.e., higher availability in the less extraverted individuals. Our results are consistent with findings showing enhanced amygdala NK1 receptor availability in patients with social anxiety disorder ${ }^{9}$, a psychopathological condition negatively associated with extraversion ${ }^{24}$. The negative association between amygdala NK1 receptor availability and extraversion is also in line with observations from animal studies showing that blockage of this receptor, by administration of NK1 receptor antagonists, increases the duration of social contact in gerbils ${ }^{36,37}$. Taken together, our results and previous findings ${ }^{9,10,36,37}$, suggest that the SP-NK1 system could potentially mediate extraverted behavior.

Exploratory whole-brain analyses further showed a negative association between extraversion and NK1 receptor availability in visual areas (cuneus and fusiform gyrus), i.e., the same direction as for the amygdala. Extraversion has previously been related to differential neural processing of positive visual stimuli, such as enhanced amygdala reactivity in response to happy facial expressions $^{46,60}$ and alterations in visual attention to emotional stimuli in parallel with activation of the fusiform gyrus ${ }^{61}$. Supporting a relation between the SP-NK1 system and extraversion, NK1 receptor antagonists have been shown to influence processing of visual stimuli of positive emotional valence ${ }^{18-20}$. For instance, a single dose of the NK1 receptor antagonist aprepitant (125 mg) improves recognition of, and alters the amygdala response to happy facial expressions ${ }^{19,20}$. In addition to visual areas, extraversion was found to be negatively associated with NK1 receptor availability within the precuneus, a structure implicated in complex tasks such as self-centered mental imagery and experience of agency ${ }^{62}$. Consistent with our findings, McCabe and colleagues demonstrated that acute administration of NK1 receptor antagonists in healthy subjects increased the activity within the precuneus during presentation of positive vs. neutral words in an emotional counting Stroop test ${ }^{20}$. However, our exploratory whole-brain analyses did not reveal any additional significant associations for either trait anxiety or neuroticism. Perhaps the association between the SPNK1 system and these negative affectivity traits are predominantly modulated by the amygdala. Alternatively, the relation in other regions could not be detected due to the restricted sample size, limiting statistical power.

Studying the role of the SP-NK1 system in anxietyrelated traits in healthy subjects may provide important insights into the neurobiological underpinnings of human anxiety and the etiology of anxiety disorders. For instance, our findings suggest that the increased susceptibility to develop psychopathological conditions related to anxious traits $^{24-26}$ could, at least in part, be mediated by individual variation in the SP-NK1 system. This system could influence anxious traits by modulating negative affectivity directly, but also by altering the propensity for approach-avoidance behavior ${ }^{3,36,37,42}$. Consistent with our findings, previous results ${ }^{18-20}$ indicate that the SPNK1 system may also influence anxious traits by affecting processing of positively valenced stimuli. In sum, our findings emphasize the need for further knowledge about the SP-NK1 system in human anxiety.

Several limitations of the present study need to be considered. First, our results are based on a limited number of participants and should be regarded as preliminary. A priori power analysis was not performed, since the study was conducted on existing PET-data from subjects serving as healthy controls in a clinical trial ${ }^{9}$, but post-hoc power analyses, based on correlation coefficients between mean NK1 receptor availability in the bilateral amygdala and each trait $(\alpha=0.05)$, indicated that the power to detect significant effects was $78 \%, 15 \%$, and $46 \%$ for trait anxiety, neuroticism, and extraversion, respectively. Also, even though our findings suggest that the SPNK1 system modulates anxiety-related traits, a prior study on patiens with personality disorder found no correlations between cerebrospinal fluid SP-like immunoreactivity and neuroticism or extraversion, but a significant relationship with aggression ${ }^{63}$. Thus, our findings need to be replicated with an adequately powered design. Moreover, the correlational approach and lack of genotyping precluded us from drawing any conclusions about the cause of the association between NK1 receptor availability and anxious traits, e.g., differences in genotype ${ }^{64}$ or exposure to life stress $^{65}$.

The high correlation observed between trait anxiety and neuroticism and the results from the PCA, implies that these traits are indeed overlapping constructs ${ }^{22,23}$, and it is not clear why NK1 receptor availability was more strongly associated with trait anxiety than neuroticism. However, although related, these constructs are not identical. Neuroticism consists of six facets, (anxiety, angry hostility, depression, self-consciousness, impulsiveness and vulnerability to stress ${ }^{23}$ and thus entails a 
broader construct than trait anxiety, as measured with STAI- $^{22}$. Moreover, results from the multiple regression analysis indicated that there is a specific association between NK1 receptor availability and trait anxiety, as the results remained significant also when controlling for neuroticism. The unexpected finding that a relation between NK1 receptor availability and neuroticism was only observed at a trend level could potentially be attributed to the limited sample size.

In the current study $\left[{ }^{11} \mathrm{C}\right] \mathrm{GR} 205171 \mathrm{~K}_{\mathrm{i}}$ is considered to reflect NK1 receptor availability, as this radiotracer has been suggested to be suitable for assessment of receptor density because of its high affinity and specificity for the NK1 receptor, as well as slow tracer-dissociation ${ }^{39}$. Although, NK1 receptor availability may be influenced by endogenous SP levels, either by direct competition with the radioligand ${ }^{66}$ or via receptor internalization ${ }^{67}$. For instance, a study on specific phobia, showed that exposure to phobic, as compared to non-phobic, stimuli was associated with reduced uptake of $\left[{ }^{11} \mathrm{C}\right] \mathrm{GR} 205171$ in the amygdala, putatively reflecting increased fear-related release of endogenous $\mathrm{SP}^{11}$. The present study, however, was performed during a passive non-stress condition and should be less influenced by fear-related changes in endogenous SP levels. Indeed, measures of state anxiety during the PET image acquisition were low and we found no relation between state anxiety levels and NK1 receptor availability during PET imaging. Accordingly, follow-up analyses showed that the association found between NK1 receptor availability and trait anxiety remained significant after controlling for state anxiety-ratings during the PET scan, and therefore it is not likely that the results could be attributed to differences in state-anxiety. However, we cannot exclude the possibility that our findings may reflect lower endogenous amygdala SP levels in anxious individuals in non-stressed conditions.

In conclusion, we demonstrate that amygdala NK1 receptor availability correlates positively with trait anxiety and negatively with extraversion. Thus, the current study indicates that the SP-NK1 system has an essential role both in modulating anxiety in psychiatric disorders and anxiety-related personality traits in healthy individuals.

\section{Acknowledgements}

The study was funded with support from the Swedish Research Council, the Swedish Research Council for Health, Working Life and Welfare, the Swedish Brain Foundation, and Riksbankens Jubileumsfond-the Swedish Foundation for Humanities and Social Sciences.

\footnotetext{
Author details

'Department of Psychology, Uppsala University, Uppsala, Sweden. ${ }^{2}$ Department of Psychology, Stockholm University, Stockholm, Sweden. ${ }^{3}$ Department of Clinical Neuroscience, Karolinska Institutet, Stockholm, Sweden. ${ }^{4}$ Department of Anesthesiology, Perioperative and Pain Medicine, Boston Children's Hospital, and Department of Psychiatry, Massachusetts General Hospital, Harvard Medical School, Boston, MA, USA. ${ }^{5}$ Nuclear Medicine and PET, Department of Surgical Sciences, Uppsala University, Uppsala,
}

Sweden. ${ }^{6}$ Medical Physics, Uppsala University Hospital, Uppsala, Sweden. ${ }^{7}$ Department of Chemistry, Uppsala University, Uppsala, Sweden. ${ }^{8}$ Department of Neuroscience, Psychiatry, Uppsala University, Uppsala, Sweden

Conflict of interest

The authors declare that they have no conflict of interest.

Publisher's note

Springer Nature remains neutral with regard to jurisdictional claims in published maps and institutional affiliations.

Received: 31 August 2017 Revised: 30 March 2018 Accepted: 13 April 2018 Published online: 28 August 2018

\section{References}

1. V. Euler, U. S., Gaddum, J. H., Von Euler, U. S. \& Goddum, J. H. An unidentified depressor substance in certain tissue extracts. J. Physiol. 72, 74-87 (1931).

2. Ohkubo, H. \& Nakanishi, S. Molecular characterization of the three tachykinin receptors. Ann. N. Y. Acad. Sci. 632, 53-62 (1991).

3. Ebner, K. \& Singewald, N. The role of substance $P$ in stress and anxiety responses. Amino Acids 31, 251-272 (2006)

4. Ribeiro-da-Silva, A. \& Hökfelt, T. Neuroanatomical localisation of Substance P in the CNS and sensory neurons. Neuropeptides 34, 256-271 (2000).

5. Bilkei-Gorzo, A. \& Zimmer, A. Mutagenesis and knockout models: NK1 and substance p. Handb. Exp. Pharmacol. 169, 143-162 (2005).

6. Mathew, S. J., Price, R. B. \& Charney, D. S. Recent advances in the neurobiology of anxiety disorders: implications for novel therapeutics. Am. J. Med. Genet. C. Semin. Med. Genet. 148C, 89-98 (2008).

7. Herpfer, I. \& Lieb, K. Substance P receptor antagonists in psychiatry: rationale for development and therapeutic potential. CNS Drugs 19, 275-293 (2005).

8. Ebner, K., Sartori, S. B. \& Singewald, N. Tachykinin receptors as therapeutic targets in stress-related disorders. Curr. Pharm. Des. 15, 1647-1674 (2009).

9. Frick, A. et al. Increased neurokinin-1 receptor availability in the amygdala in social anxiety disorder: a positron emission tomography study with [11C GR205171. Transl. Psychiatry 5, e597 (2015).

10. Furmark, T. et al. Cerebral blood flow changes after treatment of social phobia with the neurokinin-1 antagonist GR205171, citalopram, or placebo. Biol. Psychiatry 58, 132-142 (2005).

11. Michelgård, Å. et al.Symptom provocation in specific phobia affects the substance P neurokinin-1 receptor system. Biol. Psychiatry 61, 1002-1006 (2007).

12. Geracioti, T. et al. Elevated cerebrospinal fluid substance $P$ concentrations in posttraumatic stress disorder and major depression. Am. J. Psychiatry 163, 637-643 (2006).

13. Frick, A. et al. Overlapping expression of serotonin transporters and neurokinin-1 receptors in posttraumatic stress disorder: a multi-tracer PET study. Mol. Psychiatry 21, 1400-1407 (2016).

14. Mathew, S. J. et al. A selective neurokinin-1 receptor antagonist in chronic PTSD: a randomized, double-blind, placebo-controlled, proof-of-concept trial. Eur. Neuropsychopharmacol. 21, 221-229 (2011).

15. Michelson, D. et al. Lack of efficacy of L-759274, a novel neurokinin 1 (substance P) receptor antagonist, for the treatment of generalized anxiety disorder. Int. J. Neuropsychopharmacol. 16, 1-11 (2013).

16. Tauscher, J. et al. Development of the 2 nd generation neurokinin-1 receptor antagonist LY686017 for social anxiety disorder. Eur. Neuropsychopharmacol. 20, 80-87 (2010).

17. Rupniak, N. M. J. \& Kramer, M. S. NK1 receptor antagonists for depression: why a validated concept was abandoned. J. Affect Disord. 223, 121-125 (2017).

18. Pringle, A. et al. Short-term NK1 receptor antagonism and emotional processing in healthy volunteers. Psychopharmacology 215, 239-246 (2011).

19. Chandra, P. et al. NK1 receptor antagonism and emotional processing in healthy volunteers. J. Psychopharmacol. 24, 481-487 (2010).

20. McCabe, C., Cowen, P. J. \& Harmer, C. J. NK 1 receptor antagonism and the neural processing of emotional information in healthy volunteers. Int. J. Neuropsychopharmacol. 12, 1261-1274 (2009).

21. Herpfer, I. et al. Effects of substance P on memory and mood in healthy male subjects. Hum. Psychopharmacol. Clin. Exp. 22, 567-573 (2007). 
22. Spielberger, C. D., Gorsuch, R. L. \& Lushene, R. E. Manual for the State-Trait Anxiety Inventory. (Consulting Psychologists Press, Palo Alto, CA, 1970).

23. Costa, P. T. \& McCrae, R. R. Revised NEO Personality Inventory (NEO PI-R) and NEO Five-Factor Inventory (NEO-FFl) Professional Manual. (Psychological Assessment Resources, Odessa, 1992).

24. Kotov, R., Gamez, W., Schmidt, F. \& Watson, D. Linking 'big' personality traits to anxiety, depressive, and substance use disorders: a meta-analysis. Psychol. Bull. 136, 768-821 (2010).

25. Bienvenu, O. J. et al. Phobic, panic, and major depressive disorders and the five-factor model of personality. J. Nerv. Ment. Dis. 189, 154-161 (2001).

26. Lahey, B. B. Public health significance of neuroticism. Am. Psychol. 64, 241-256 (2009).

27. Cuijpers, P., Smit, F., Penninx, B. W. J. H., de Graaf, R., ten Have, M. \& Beekman, A. T. F. Economic costs of neuroticism: a population-based study. Arch. Gen. Psychiatry 67, 1086-1093 (2010).

28. Eysenck, H. J. The Biological Basis of Personality. (Charles C. Thomas, Springfield, IL, 1967).

29. Canli, T. Functional brain mapping of extraversion and neuroticism: learning from individual differences in emotion processing. J. Pers. 72, 1105-1132 (2004).

30. Pang, $Y$. et al. Extraversion and neuroticism related to the resting-state effective connectivity of amygdala. Sci. Rep. 6, 35484 (2016).

31. Etkin, A. et al. Individual differences in trait anxiety predict the response of the basolateral amygdala to unconsciously processed fearful faces. Neuron $\mathbf{4 4}$ 1043-1055 (2004).

32. Landgraf, R. \& Wigger, A. High vs low anxiety-related behavior rats: an animal model of extremes in trait anxiety. Behav. Genet. 32, 301-314 (2002).

33. Brunelli, S. A. Development and evolution of hidden regulators: selective breeding for an infantile phenotype. Dev. Psychobiol. 47, 243-252 (2005).

34. Sartori, S. B., Ebner, K., Muigg, P., Landgraf, R. \& Singewald, N. Differences in substance $P$ neurotransmission between rats with high vs. low trait anxiety/ depression. J. Neurochem. 94(Suppl. 2), 229 (2005).

35. Schott, A. L. \& Zimmerberg, B. Effects of Neurokinin-1 receptor inhibition on anxiety behavior in neonatal rats selectively Bred for an infantile affective trait. Pharmacology 5, 859-864 (2014).

36. Cheeta, S. et al. Anxiolytic actions of the substance P (NK1) receptor antagonist $\mathrm{L}-760735$ and the $5-\mathrm{HT} 1 \mathrm{~A}$ agonist 8-OH-DPAT in the social interaction test in gerbils. Brain Res. 915, 170-175 (2001).

37. Gentsch, C., Cutler, M., Vassout, A., Veenstra, S. \& Brugger, F. Anxiolytic effect of NKP608, a NK1-receptor antagonist, in the social investigation test in gerbils. Behav. Brain. Res. 133, 363-368 (2002).

38. Gardner, C. J. et al. GR205171: a novel antagonist with high affinity for the tachykinin NK1 receptor, and potent broad-spectrum anti-emetic activity. Regul. Pept. 65, 45-53 (1996).

39. Bergström, M. et al. Brain uptake and receptor binding of two [11C]labelled selective high affinity NK1-antagonists, GR203040 and GR205171 - PET studies in rhesus monkey. Neuropharmacology 39, 664-670 (2000).

40. Griffante, C., Carletti, R., Andreetta, F. \& Corsi, M. [3H]GR205171 displays similar NK1 receptor binding profile in gerbil and human brain. Br. J. Pharmacol. 148, 39-45 (2006).

41. Boyce, S. et al. Intra-amygdala injection of the substance P (NK1 receptor) antagonist L-760735 inhibits neonatal vocalisations in guinea-pigs. Neuropharmacology 41, 130-137 (2001).

42. Carvalho, M. C., Santos, J. M., Bassi, G. S. \& Brandão, M. L. Participation of NK1 receptors of the amygdala on the processing of different types of fear. Neurobiol. Learn. Mem. 102, 20-27 (2013).

43. Ebner, K., Rupniak, N. M., Saria, A. \& Singewald, N. Substance $P$ in the medial amygdala: emotional stress-sensitive release and modulation of anxietyrelated behavior in rats. Proc. Natl Acad. Sci. USA 101, 4280-4285 (2004).

44. Haas, B. W., Omura, K., Amin, Z., Constable, R. T. \& Canli, T. Functional connectivity with the anterior cingulate is associated with extraversion during the emotional Stroop task. Soc. Neurosci. 1, 16-24 (2006).
45. Aghajani, M. et al. Neuroticism and extraversion are associated with amygdala resting-state functional connectivity. Cogn. Affect. Behav. Neurosci. 14, 836-848 (2013).

46. Canli, T., Sivers, H., Whitfield, S. L., Gotlib, I. H. \& Gabrieli, J. D. E. Amygdala response to happy faces as a function of extraversion. Science 296, 2191 (2002).

47. Sheehan, D. V. et al. The Mini-International Neuropsychiatric Interview (M.I.N.I.): the development and validation of a structured diagnostic psychiatric interview for DSM-IV and ICD-10. J. Clin. Psychiatry 59, 22-33 (1998).

48. Patlak, C. S., Blasberg, R. G. \& Fenstermacher, J. D. Graphical evaluation of blood-to-brain transfer constants from multiple-time uptake data. J. Cereb. Blood Flow. Metab. 3, 1-7 (1983).

49. Patlak, C. S. \& Blasberg, R. G. Graphical evaluation of blood-to-brain transfer constants from multiple-time uptake data. Generalizations. J. Cereb. Blood Flow. Metab. 5, 584-590 (1985).

50. Hietala, J. et al. Visualization and quantification of neurokinin-1 (NK1) receptors in the human brain. Mol. Imaging Biol. 7, 262-272 (2005).

51. Caberlotto, L. et al. Neurokinin 1 receptor and relative abundance of the short and long isoforms in the human brain. Eur. J. Neurosci. 17, 1736-1746 (2003).

52. Svarer, C. et al. MR-based automatic delineation of volumes of interest in human brain PET images using probability maps. Neuroimage 24, 969-979 (2005).

53. Maldjian, J. A., Laurienti, P. J., Kraft, R. A. \& Burdette, J. H. An automated method for neuroanatomic and cytoarchitectonic atlas-based interrogation of fMRI data sets. Neuroimage 19, 1233-1239 (2003).

54. Engman, J. et al. Age, sex and NK1 receptors in the human brain - a positron emission tomography study with [(11)C]GR205171. Eur. Neuropsychopharmacol. 22, 562-568 (2012).

55. Nyman, M. J. et al. Gender and age affect NK1 receptors in the human brain a positron emission tomography study with [18F]SPA-RQ. Int. J. Neuropsychopharmacol. 10, 219-229 (2007).

56. Källmén, H., Wennberg, P. \& Bergman, H. Psychometric properties and norm data of the Swedish version of the NEO PI-R. Nord. J. Psychiatry 65, 311-314 (2011).

57. Costa, P. T. \& McCrae, R. R. NEO PI-R Manual-svensk version (swedish version). (Hogrefe Psykologiförlaget AB, Stockholm, 2003).

58. Cremers, H. R. et al. Neuroticism modulates amygdala-prefrontal connectivity in response to negative emotional facial expressions. Neuroimage 49, 963-970 (2010).

59. Verduyn, P. \& Brans, K. The relationship between extraversion, neuroticism and aspects of trait affect. Pers. Individ. Dif. 52, 664-669 (2012).

60. Canli, T. et al. An fMRI study of personality influences on brain reactivity to emotional stimuli. Behav. Neurosci. 115, 33-42 (2001).

61. Amin, Z., Todd Constable, R. \& Canli, T. Attentional bias for valenced stimuli as a function of personality in the dot - probe task. J. Res. Pers. 38, 15-23 (2004).

62. Cavanna, A. E. \& Trimble, M. R. The precuneus: a review of its functional anatomy and behavioural correlates. Brain 129, 564-583 (2006).

63. Coccaro, E. F., Lee, R., Owens, M. J., Kinkead, B. \& Nemeroff, C. B. Cerebrospinal fluid substance P-like immunoreactivity correlates with aggression in personality disordered subjects. Biol. Psychiatry 72, 238-243 (2012).

64. Schank, J. R. et al. Tacr1 gene variation and neurokinin 1 receptor expression is associated with antagonist efficacy in genetically selected alcohol-preferring rats. Biol. Psychiatry 73, 774-781 (2013).

65. Hwang, B. H., Katner, J. \& lyengar, S. Corticotropin-releasing factor mRNA and substance $P$ receptor binding in the paraventricular hypothalamic nucleus, central nucleus of the amygdala, and locus coeruleus of sprague-dawley rats following restraint-induced stress. J. Mol. Neurosci. 25, 239-250 (2005).

66. Hargreaves, R. Imaging substance $P$ receptors (NK1) in the living human brain using positron emission tomography. J. Clin. Psychiatry 63, 18-24 (2002).

67. Mantyh, P. W. et al. Rapid endocytosis of a G protein-coupled receptor: substance $P$ evoked internalization of its receptor in the rat striatum in vivo. Proc. Natl Acad. Sci. USA 92, 2622-2626 (1995). 